\title{
Intrathecal baclofen: does tolerance occur?
}

\author{
M N Akman MD,${ }^{1} \mathrm{P}$ G Loubser MB ChB,${ }^{2}$ W H Donovan MD,${ }^{3}$ M E O'Neill RN, ${ }^{4}$ \\ C D Rossi MS ${ }^{5}$ \\ ${ }^{1}$ Assistant Professor, Department of Physical Medicine and Rehabilitation, Inonu \\ University Medical School, Arastirma ve Uygulama Hastanesi, Malatya, Turkey; \\ ${ }^{2}$ Associate Professor, Department of Anesthesiology, University of Texas, Houston; \\ ${ }^{3}$ Executive Vice President for Medical Affairs, The Institute for Rehabilitation and \\ Research and Professor and Chairman, Department of Physical Medicine and \\ Rehabilitation, University of Texas, Houston; ${ }^{4}$ The Institute for Rehabilitation and \\ Research; ${ }^{5}$ Assistant Research Professor, Department of Physical Medicine and \\ Rehabilitation, Baylor College of Medicine, Houston, Texas, USA.
}

\begin{abstract}
Concern over the development of tolerance in patients on continuous intrathecal baclofen therapy has arisen as this new form of treatment for spasticity has gained wider use. We have studied time-dose relationships in 18 spinal cord injured patients who have undergone intrathecal baclofen infusion pump implantation since February 1988 in our facility. Our data show that there was a significant increase in baclofen dosage needed to control spasticity during the first 12 months post implantation. After 12 months, however, no significant change in dosage requirement was detected. In addition, there was no significant difference between completely and incompletely spinal cord injured patients with regard to both the initial dose and the tolerance trend.
\end{abstract}

Keywords: intrathecal baclofen; spasticity; spinal cord injury; tolerance.

\section{Introduction}

Continuous intrathecal baclofen infusion has been shown to be a safe and effective treatment for severe spasticity of spinal cord origin, and has become increasingly accepted as an alternative for surgery in spinal cord injured (SCI) patients with this problem. ${ }^{1-11}$ Nevertheless, concern over whether patients will develop tolerance remains a controversial issue affecting clinicians' decisions whether to use this modality or not.

Tolerance is defined as a phenomenon manifested by an escalation of the dose

This study will be presented as a poster in IRMA-VII Washington DC, April 9-16, 1994.

Correspondence: William H Donovan MD, The Institute for Rehabilitation and Research, 1333 Moursund Avenue, Houston, Texas 77030, USA. required to produce a previously obtained effect or by the decrement of the effect produced by a given dose of drug with continued administration. ${ }^{12}$ Baclofen (Beta4-chlorophenyl-gamma-aminobutyric acid) is an agonist of gamma-aminobutyric acid-B (GABA-B) receptors which are very superficial in the spinal cord. ${ }^{13} \mathrm{~A}$ theory as to why tolerance develops for drugs which exert their pharmacological effects by interaction with specific receptors is that repeated administration of the agonist causes either a reduction in receptor number or an uncoupling of the receptor to effector molecules. This results, either way, in an increase in the concentration of a given agent necessary to achieve the fractional occupancy in order to evoke a given effect. ${ }^{14}$

In this study, we investigated the relation 
between time and the required intrathecal baclofen dose needed to keep spasticity at an acceptable level, and thereby see whether tolerance was a factor in our patients.

\section{Materials and methods}

Eighteen patients with SCI ( 5 complete, 13 incomplete) who had undergone continuous intrathecal baclofen infusion pump (SynchroMed, Medtronics Inc) implantation in our facility between February 1988 and May 1991 for severe spasticity were studied. All patients had temporary baclofen (Lioresal, Ciba-Geigy) infusions prior to pump implantation, in order to find a dosage of baclofen that optimally controlled spasticity without resulting in flaccidity, and which was associated with patient satisfaction. After pump implantation, patients were seen on a monthly basis for refills and clinical investigation. We documented the initial and subsequent doses of baclofen every 3 months post implantation. We also measured the intensity of spasticity using the Ashworth scale (Table I) at the same intervals.

\section{Results}

During a mean follow up period of 29.9 months (6-48 months), spasticity was kept under acceptable control (Ashworth grade 1-2). There were no significant differences between the mean Ashworth grades at the 3-monthly intervals throughout the study. Only 10 patients have been followed for more than 24 months. The data are still not sufficient for statistical analysis after 24 months because of the drop off rate of patients after that juncture. For that reason, we analyzed the data for the first 24 months only. All of the patients were followed for at least 6 months, 17 for 12 months, 16 for 18 months, 15 for 21 months and 14 for 24 months. All patients showed a significant trend to increase their dosage over the 24-month period (Fig 1) beginning with an initial dosage of $201.5 \mu \mathrm{g} /$ day $(\mathrm{SD}=104.9)$. Least squares regression analysis of the dosages on 3-monthly intervals indicated that within the first 12-month period, the patients showed a significant positive linear trend at $p<0.0009$ (Fig 2). But additional analysis indicated that there was no trend in increase of dosage from the 12th month to the 24th month (Fig 3). We also analyzed the complete and incomplete injury groups separately. Least squares regression analysis

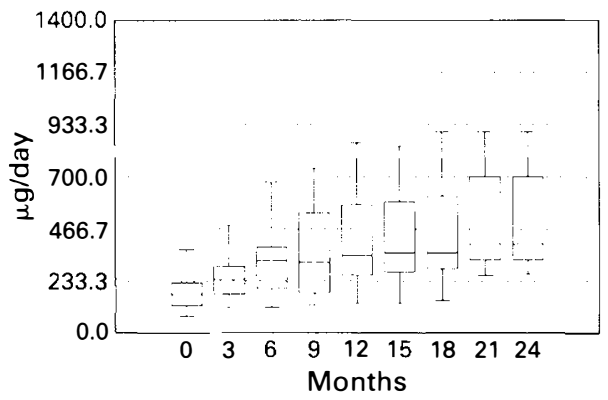

Figure 1 Box plots graphic of intrathecal baclofen doses of all patients for 3-month intervals over 24 months.

Table I Intensity of spasticity using the Ashworth scale

\begin{tabular}{ll}
\hline Grade & Degree of muscle tone \\
\hline 1 & No increase in tone \\
2 & $\begin{array}{l}\text { Slight increase in tone, giving a 'catch' when affected part is moved in flexion or } \\
\text { extension }\end{array}$ \\
3 & More marked increase in tone, but affected part easily flexed \\
4 & Considerable increase in tone, passive movement difficult \\
5 & Affected part rigid in flexion or extension
\end{tabular}

Ashworth scale-Ashworth grade is calculated by summing grades for hip flexion, hip abduction, knee flexion and ankle dorsiflexion on each side and then dividing by 8 . 
indicated a significant linear increase over the first 12 months $(p=0.0009)$ with an initial dosage of $210.5 \mu \mathrm{g} / \mathrm{day}(\mathrm{SD}=121.9)$ for incompletely injured patients (Figs 4,5 ) and a significant linear increase over the first 12 months $(p=0.0009)$ with an initial dosage of $180.0 \mu \mathrm{g} /$ day $(\mathrm{SD}=48.1)$ for completely injured patients (Figs 6, 7). There was no significant increasing trend between the 12th and the 24th month for either group. We compared the complete

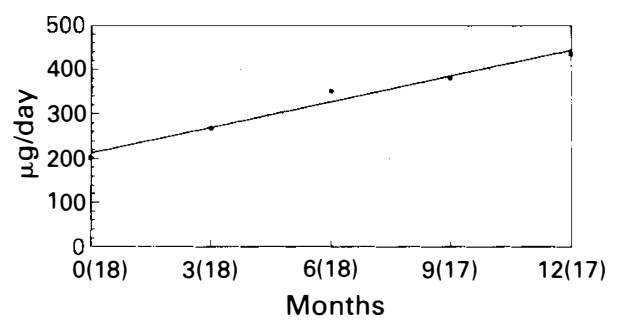

Figure 2 Time-dose relation for all patients in the first 12 months. Numbers of patients for the months are shown in parentheses.

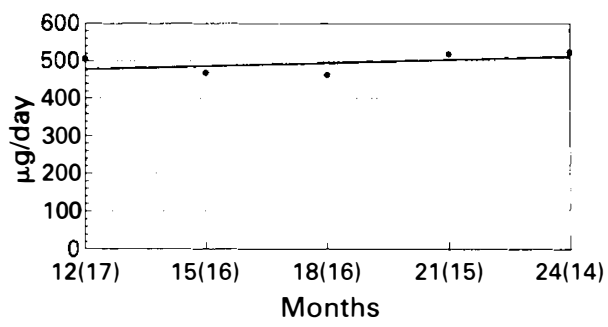

Figure 3 Time-dose relation for all patients between the 12th and 24th month. Numbers of patients for the months are shown in parentheses.

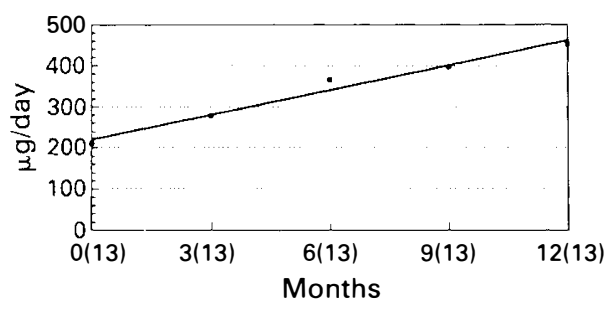

Figure 4 Time-dose relation for incomplete injury patients in the first 12 months. Numbers of patients for the months are shown in parentheses.

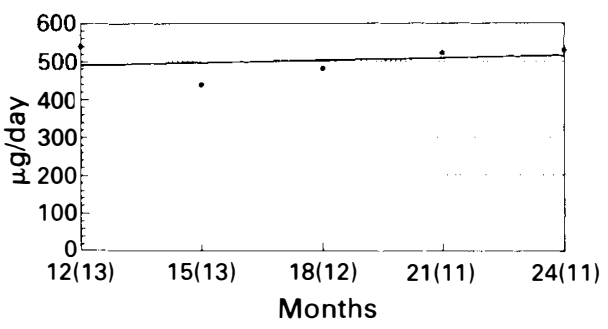

Figure 5 Time-dose relation for incomplete injury patients between the 12th and 24th month. Numbers of patients for the months are shown in parentheses.

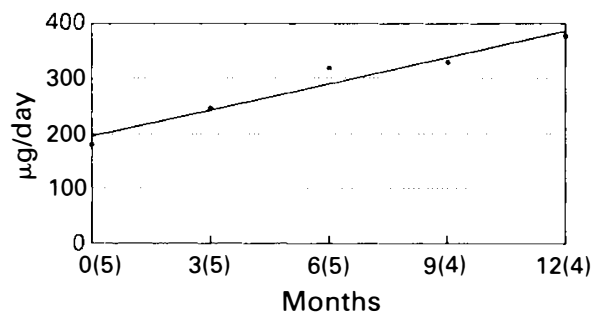

Figure 6 Time-dose relation for complete injury patients in the first 12 months. Numbers of patients for the months are shown in parentheses.

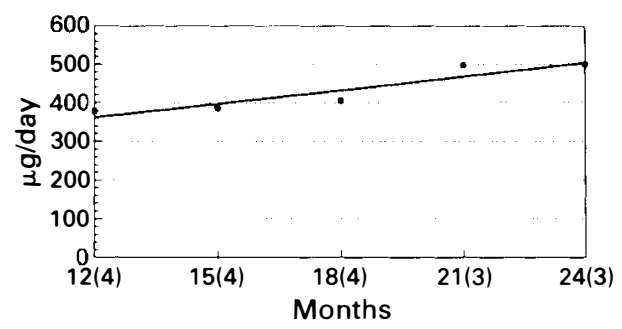

Figure 7 Time-dose relation for complete injury patients between the 12th and 24th month. Numbers of patients for the months are shown in parentheses.

and incomplete injury groups with regard to initial dosages and found no significant difference. Similarly, we tested the null hypothesis that there was no significant difference in the slopes between the linear fit of dosages for both groups for the first and second 12-month periods, by incorporating an indicator variable representing slopes. The analysis indicated no significant difference between the slopes. 


\section{Discussion}

Penn and Kroin, the first authors who proposed intrathecal baclofen therapy for spinal spasticity, ${ }^{15}$ were also the first authors who pointed out the problem of tolerance. ${ }^{1}$ In their series of 7 patients with spinal spasticity (due to SCI and multiple sclerosis), they reported a gradual increase in dose during the first 3-4 months in 6 patients, which extended up to 2 years in 2 patients. Ochs et al, on the other hand, reported that most of their patients reached a stable dose in 3 months except for a few patients who had experienced an increasing number of spasms even after one year, in their study with 28 patients, 10 of whom had SCI. ${ }^{6}$ Lazorthes et al stated that they had not observed any case of pharmacological tolerance in their series of 18 patients, 7 of whom had SCI, with an average follow up of 18 months. ${ }^{8}$ Sahuquillo et al suggested that tolerance was observed only in complete SCI patients, based on their series of 9 patients ( 5 complete, 4 incomplete) with an average follow up of 18 months. ${ }^{10}$ They also reported that dosage increases were statistically significant in the first 12 months, but not between 12 and 24 months. Recently,
Meythaler et al reported the occurrence of tolerance in their 12-month follow up study in their series, including $5 \mathrm{SCI}$ patients. ${ }^{11}$

Our data with 18 SCI patients, 5 complete and 13 incomplete, clearly show that tolerance to baclofen administered intrathecally is observed within the first 12 months, but after the 12th month patients reach a stable dose and do not require further dosage increases. Further, there is no difference between completely and incompletely injured patients with regard to dosage over time. None of our patients discontinued treatment due to side effects or from complications with high doses, thus safety of this modality was not a problem in our series. We suggest that tolerance per se should not dissuade one from choosing intrathecal baclofen pump implantation in SCI patients with severe intractable spasticity refractory to traditional modalities.

\section{Acknowledgement}

This work was supported in part by a grant from the National Institute on Disability and Rehabilitation Research, US Department of Education, Grant Number H133N00016-91.

\section{References}

1 Penn RD, Kroin JS (1987) Long-term intrathecal baclofen infusion for treatment of spasticity. J Neurosurg 66(2): 181-5.

2 Muller H, Zierski J, Dralle D, Borner U, Hoffmann O (1987) The effect of intrathecal baclofen on electrical muscle activity in spasticity. $J$ Neurol 234(5): 348-52.

3 Zierski J, Muller H, Dralle D, Wurdinger T (1988) Implanted pump systems for treatment of spasticity. Acta Neurochir Suppl (Wien) 43: 94-9.

4 Parke B, Penn RD, Savoy SM, Carcos D (1989) Functional outcome after delivery of intrathecal baclofen. Arch Phys Med Rehabil 70(1): 30-2.

5 Penn RD, Savoy SM, Corcos D, Latash M, Gottlieb G, Parke B et al (1989) Intrathecal baclofen for severe spinal spasticity. $N$ Engl J Med 320(23): 1517-21.

6 Ochs G, Struppler A, Meyerson BA, Linderoth B, Gybels J, Gardner BP, Teddy P et al (1989) Intrathecal baclofen for long-term treatment of spasticity: a multi-center study. J Neurol Neurosurg Psychiatry 52: 933-9.

7 Broseta J, Garcia-March G, Sanchez-Ledesma MJ, Anaya J, Silva I (1990) Chronic intrathecal baclofen administration in severe spasticity. Stereotact Funct Neurosurg 54-55: 147-53.

8 Lazorthes Y, Sallerin-Caute B, Verdie JC, Bastide R, Carillo JP (1990) Chronic intrathecal baclofen administration for control of severe spasticity. J Neurosurg 72: 393-402.

9 Loubser PG, Narayan RK, Sandin KJ, Donovan WH, Russel KD (1991) Continuous infusion of intrathecal baclofen: long-term effects on spasticity in spinal cord injury. Paraplegia 29(1): 48-64.

10 Sahuquillo J, Muxi T, Noguer M, Jodar R, Closa C, Rubio E et al (1991) Intraspinal baclofen in the treatment of severe spasticity and spasms. Acta Neurochir (Wien) 110: 166-173.

11 Meythaler JM, Steers WD, Tuel SM, Cross LL, Haworth CS (1992) Continuous intrathecal baclofen in spinal cord spasticity. Am J Phys Med Rehabil 71: 321-7.

12 Stevens CW, Yaksh TL (1989) Potency of infused spinal anti-nociceptive agents is inversely related to magnitude of tolerance after continuous infusion. J Pharmacol Exp Ther 250(1): 321-7. 
13 Price GW, Wilkin GP, Turnbull MJ, Bowery NG (1984) Are baclofen-sensitive GABA-B receptors present on primary afferent terminals of the spinal cord? Nature 307: 71-4.

14 Golstein A, Aronow L, Kalman SM, editors (1974) Principles of Drug Action. John Wiley \& Sons, New York: 459-68.

15 Penn RD, Kroin JS (1984) Intrathecal baclofen alleviates spinal cord spasticity. Lancet 1: 1078. 